\title{
Uncertainty and organizationality in economic systems
}

\author{
Evgeny A. Kuzmin \\ Department of Regional Economic Policy and Economic Security \\ Institute of Economics of the Ural Branch of Russian Academy of Sciences \\ Ekaterinburg, Russian Federation
}

\begin{abstract}
The paper is devoted to the issue of clarifying the organizational order of the construction and functioning of economic systems. In the review of the literature, a meaningful juxtaposition of the concepts of a socio-economic and organizational-economic system is considered; their analysis allows establishing that at the heart of conceptual pluralism there is a single fundamental cornerstone - organization. The authors have discovered the institutional basis of organizationality in the economy through a comtlegtive institution as establishing the basic "rules of play" (the design of the economic system). In the course of the study, it is argued that self-organization is a result of uncertainty management, while at the same time the latent ability to self-organize, restore or form the organizational order is manifested in the organizational and economic system. Thus, organizationality in the economy is perceived as a primacy of the determinism of uncertainty manifestation. The causes of the manifestation of self-organization are concentrated in the structural arrangement of the system and the coherence of its design. These and other provisions made it possible to propose a definition of the organizational and economic system.
\end{abstract}

Keywords-uncertainty; economic system; organization; economic mechanism; comtlegtive institution; self-organization.

\section{INTRODUCTION}

Uncertainty, being a universal characteristic of the orderliness of the course of various processes and phenomena, can be involved in the solving of a wide range of scientific problems. The study of the structural relationship between uncertainty and certainty is one of many examples of theoretical and methodological comprehension of the role of uncertainty both in achieving the sustainability of a system's development and in designing its future state. At the same time, the universality of the category does not exclude the need for more precise and scientific substantiation of the general object of study.

The authors deliberately focus on economic systems as an object of investigation, in which the effect of uncertainty is spread throughout the entire space of the system. However, the identity of the penetration of uncertainty does not yet indicate the strength of its manifestation in different space-time coordinates. The boundaries of the structural elements of the system create an inhomogeneous density of uncertainty and thus notice the influence of intensity factors and the order of interaction between objects on the nature of its distribution. As a result, an essential feature of the subject of research should be organizationality, perceived as a primacy of the determinism of manifestation of uncertainty.
The study of certain aspects of the functioning of the economic mechanism requires the definition of a driving, fundamental factor. For this study, this factor is the organizational order that creates uncertainty in social and economic life. Precisely, the issues of rational organization of the economy, optimization of the ongoing processes, increasing their effectiveness, balancing between economic structures occupy a central place in modern research concepts. Confirmation of this can be found in the publications by Kleiner, who rightly asserts that in modern conditions "special importance is given to the study of generalized theoretical models of rational organization of the economy, based on the principles of the system approach in general and the new theory of economic systems in particular" [1]. It becomes obvious that the orderliness and order parameters play a significant role not only in revealing the content of the system as a scientific category, but also in explaining the phenomena of disorganization, the mechanisms for restoring the organizational structure (self-organization) and the actual uncertainty.

\section{LITERATURE REVIEW}

The concepts "socio-economic system" and "organizational-economic system" are successfully used in scientific research without causing any special disputes. At the same time, the theoretical and methodological basis for the study of socio-economic systems is very extensive. Many scholars are engaged in studying this problem: Baumgartner, Burns, and DeVille - in the sphere of formation of socioeconomic systems [2]; Halbach, Szirmai - in the sphere of identifying the conditions of development and sustainability of such development [3, 4]; Albin, Haitani - in the sphere of the system's state analysis [5,6]; Levcik, Choudhury - in institutional description of the functioning mechanism [7, 8]; Choudhury, DeSouza, Gowdy - in disclosure of connected areas of co-evolution of socio-economic system being integral parts of that system $[8,9,10]$.

Noteworthy in this regard is Novikov's research on the structure of the theory of management of socio-economic systems. Thus, in his presentation, the central element of the theory is "the category of organization" [11]. Jaffee takes a similar position, highlighting a number of analytical levels of a socio-economic system [12]. In addition to international, social and individual, Jaffee distinguishes the organizational level in such systems. Its feature is in intra- and interorganizational structures that require coordination of behavior, management of dynamic development, and choice of 
principles of rationality. Reinforcement of the position on the importance of organizational order in the socio-economic system is also in its characteristic attributes. Thus, Choudhury puts convincing arguments in favor of the fact that "the general socio-economic system includes the market, the surrounding systems [subsystems. - Note by the authors], its representation in the state structure [and structure of institutions] through the organization of decentralized participation" [13], where rules, norms and mechanisms, or rather their execution, play a significant role in maintaining organizational stability.

As it was noted, the basis of conceptual pluralism is a single fundamental cornerstone - the economic system. In the view of Kleiner, the economic system "means a system which participates in four known general economic processes: production, consumption, distribution and exchange" [14]. There arises a natural question: which is the role of supporting elements - the institution as a connecting substance between the objects of the system and the natural needs of individuals as a flywheel, which drives a chain of general economic processes. The dialectical problem of identifying the economic system and its subsystems encounters the complexity of setting boundaries. A special organizational order gives the systems a distinctive feature in the principles of the rationality of the behavior of the subjects and the goals of this behavior. The distinction of institutional space means only physical boundaries, not excluding the effects of system adhesion. Thus, the picture of the economic system is created mainly through the institutional order, the specification of the organizational structure. Other factors seem to delineate internal boundaries, but for subsystems already.

Epistemologically equivalent is the definition of the economic system given by Vechkanov and Vechkanova as "a set of interrelated and ordered components of the economy" [15], where "the economic system is a set of links between producers and consumers of material and non-material goods." Returning to the works by Kleiner, one can pay attention to the typology of economic systems that he offers, while the principle of object analogies is used as one of the criteria for their subdivision [16]. Each class of systems has a kind of "certainty/uncertainty of the boundaries of the system in time and space," on which the analogy is constructed [17].

As one can see, the property of the parameters by the uncertainty of their state plays a key role in justifying the principle of the organizationality of economic systems. It is the organizationality that manifests the structural nature of uncertainty in the design of the system itself, its saturation with economic agents, frequency and depth of the connections between them. With that, however, the determinants of the entropy of the economic system are not limited.

Thus, the component of the organization is internally embedded in the socio-economic system. Parallel use of conceptual descriptors of sociality and organizationality, in the authors' opinion, should not cause fundamental contradictions. In both cases, it is primarily about the economic system, and clarification of the aspects of studying its functioning constitutes a particular scientific task. In contrast to sociality, organizationality makes it possible to maximally approximate the model of the system being developed to its real prototype, focusing not on the behavioral aspect of individuals (subjective factor), but on conditions conducive to such behavior, mainly on the frequency of interrelations, structure and population of objects (reliable predictors). In this regard, it seems expedient to turn to the research of various forms of manifestation of organizationality in the economy.

\section{ECONOMIC SYSTEM VS. ECONOMIC MECHANISM}

Theoretical and methodological practice is based on differing prerequisites for scientific substantiation and the argumentation of the admissibility of the term "organizational and economic system," which was considered above. A review of the scientific literature has shown that in most cases a similar but conventionally not identical definition of "organizational and economic mechanism" is used. Apparently, the mechanism is considered as a system-forming element. This is indicated by numerous fundamental and applied works. Among such studies, one can single out the works by Sarkisyan, Akhundov \& Minaev [18], Krayukhin [19], Kovalenko, Zinchuk, Kochetkova et al. [20], Kochikyan, Koshkin \& Lyubinetskiy [21], Alpatov [22], Ponomaryova [23], etc.

The mechanism, in the authors' opinion, is an ordered structure of interdependencies and conditional relationships between agents. The mechanism in this case has several features of formation. First, it differs in some respects in causal and logical-structural regularities that are in the focus of research attention. Second, the emergence of an economic system occurs simultaneously with the emergence of its inherent mechanism, in the mainstream of which the processes of creation, distribution and redistribution of benefits occur. Third, the manifestation of regularities in the system and the emergence of a mechanism is a consequence of the consolidation of a certain paradigm of rationality, efficiency and optimality of behavior.

It seems that any system a priori has a characteristic macro-mechanism, being the only one. After all, it is the structure of connections, the predictability of feedback responses to disturbances that unite cardinally different elements into one single, monolithic, homogeneous thing. Undoubtedly, among researchers there is a different vision of the organizational-ecological mechanism. Its main aspects can be represented in the form of two basic groups:

(1) as a descriptive development tool;

(2) as a management tool (in innovation - Todosiychuk and Popkov [24], in investment - Ayupova [25], in strategic management - Tsogoyev [26], etc.).

The versatility of the organizational and economic mechanism of a system is not surprising. All economic processes and actions are in the field of influence of the determinative mechanism, without which, as it seems, the system will be incompetent. However, for all the validity of its value, one can see the absence of a clear and universal definition. It is worth paying attention to the shift in the categories of system and mechanism in the designation of the organizational and economic structure of certain phenomena. If a system is a kind of formation of a certain integrity and 
unity of a set of elements, then a mechanism peculiar to it reveals the order of organization of elements filling the system, the features of the links between them and, most importantly, unique determinants of "action and result."

In this connection, it should be emphasized that the notions of the organizational and economic system and mechanism have narrow and wide interpretations. As a result, their correct perception in practice is distorted. Of course, the boundaries of the economic system are vast, and the combination of the social and institutional layers, in fact, replaces the designation of cohesive categories of organizationality and sociality. Confirmation of this can be found in the words by Rimer, Kasatov and Matienko: "...the organizational and economic mechanism is the rules governing interaction ..." [27] between participants. Accepting this inference, one can reasonably draw analogies between organizational-economic mechanism and institution in the most general sense of their perception. In their perception, the mechanism, in addition to the rules, includes the obligations assumed by the participants in their interactions, conditions and behavioral features [27]. In other words, the existing rules of play are taken, which is nothing more than a macroinstitution.

Thus, the organizational and economic mechanism acts as a sublimative institutional formation with specific features constraints, opportunities, variability, and accordingly, the uncertainty of the dominant position. A natural or artificial transformation of the rules of play renews the face of the organizational economic mechanism and, consequently, the image of the organizational and economic system.

\section{UNCERTAINTY IN THE INSTITUTIONAL DESCRIPTION OF ORGANIZATIONAL AND ECONOMIC SYSTEMS}

The problems of the development of economic relations are emphasized in academic studies, which fix the structural composition of elements of the economic system as the primary basis of study. In this context, it is worth considering the existence of an epistemological gap in the theory and methodology of the conjugate study of economic systems and their institutional framework. The use of the widespread concept of "institutional environment" is unacceptable here, because such environment is for the most part heterogeneous, consisting of many different institutions. To solve the sounded problem, the authors propose to introduce into the scientific revolution the notion of a comtlegtive institution 1 . In essence, a comtlegtive institution is a constitution of the economic system. Since core rules and instructions for the proper behavior of agents are present in all institutions irrespective of their functions and affiliation, acting as the basis for the formation of other derived rules and norms, the comtlegtive institution solves the problem of macro regulation and replaces the organizational and economic mechanism as a result. Rather, the comtlegtive institution sets the general framework of the mechanism, reveals the formation vector of the conditioning regularities, and indicates the direction of development of the constituent elements of the system.

1 Etymologically, the term "comtlegtive" term is formed from Latin tectum (cover, roof), legis (regulation, rule, order) and communitas (common, public, communication)
The point of view of Sarkisyan, Akhundov and Minaev is noteworthy; they put that "... the organizational and economic system is viewed as a self-adjusting object of a dynamic nature that is under the influence of the external environment and internal processes" [28].

Achieving the continuity of promotion of the economic flywheel is hampered by errors in substituting "outputs," the results of some operations and the "inputs" of the subsequent ones. There arises the uncertainty about the results of economic processes and the future state of the whole system through a sequence of cascading failures. Undoubtedly, changes in the rules of play create a special type of uncertainty that affects the stability of the participants in the game. Uncertainty of this kind is capable, in a wavy effect, to increase the uncertainty of traditional species, such as uncertainty of the environment, decision-making and consequences of these decisions. As a result, the dynamic selfadjustment mentioned by Sargsyan et al. is a manifestation of the self-organization of a complex system.

The impact of the external environment and internal processes on the self-adjustment of the system does not lose its relevance. In a situation of evolutionary shift, the changing source of business becomes the main source of uncertainty, which, as is known, leads to an increase in uncertainty in all other seemingly routine activities. It is worth noting that it is economic routines that are free from the uncertainty of new expectations. Processes and operations, repeated with time, with each time become more specific, even to some extent constant. The replacement of some routines with new ones can be a consequence of changes in the institutional organization of the system, become a harbinger of an evolutionary leap, which in this case may have not entirely productive consequences.

\section{SELF-ORGANIZATION IN THE ORGANIZATIONAL AND ECONOMIC SYSTEM}

The organizational and economic system, being open and stochastic, is in contact with the external environment, exchanges resources and information, creates channels for direct communication and feedback. The inevitable change in the "requests" of the external environment leads to objective prerequisites for the correspondence of the internal form and content to the optimal level of balance between such "requests" and the internal stability of the system, its goals and capabilities. The final achievement of consensus supports the homeostasis of the organizational and economic system. In other words, the level of system uncertainty remains in the admissible corridor of deviations. This, in fact, is the selfadjustment of the system, that is, self-organization, the emergence of which is most clearly visible in moments of the highest chaos and uncertainty.

It may seem that the power of self-organizing processes is concentrated in the stability of the managed order of the system, in its invariance, but this is not so. If in the first case one can speak about dynamic self-organization, then a range of phenomena remains unreached, where a complete restoration is possible only if the object or some system approaches the edge of its self-destruction. Consequently, selforganization has both a dynamic and a discrete origin. It seems 
that the reason for this is the lack of an embedded element of continuous monitoring, which seems to play the role of a kind of a guard against random errors in the alignment of the organizational structure of an economic system or some object.

In the problematics of uncertainty in self-organization, a number of definitions have remained unreached, in which attention is focused on inalienable attributes - hierarchy and harmony of the internal structure. A sufficiently capacious definition of the system is given by Fedorovich [29], implying an interdependent set of elements - organizationally, economically, and sometimes technologically interconnected, lower-level subsystems, while clarifying that the final result of the activity of each link (element) of the lower-level system serves as the initial resource for the system (or subsystem) of a higher rank. Synectically similar is the interpretation of the essence of organizational and economic system in Kulman [30], where emphasis is placed on a certain aggregate or sequence of economic phenomena in the conditioning mechanism of the functioning of the system.

In a variety of scientific definitions, one can trace the linkage of the control function with the strictness of the internal structure of the system. Indirect and direct indications of this are available in the studies of Rybin, Kochikyan, Koshkin, Lyubinetskiy, Gritans, and others. Indeed, management in all branches of social activity rests on certain hierarchical subordinates of one object to another. As is known, determinative links between the elements of the system are part of the mechanism of its functioning, which makes it possible to design an organizational concept of the internal arrangement of the entire system. The validity of this conclusion is reinforced by the ideas of Drucker, who believes that "... management is a special kind of activity that turns the unorganized crowd into an effective, purposeful and productive group" [31]. Important here is the sign of the organization, or rather, the presence or absence of organizational order in the system.

Management initially comes from the fact that between the elements or objects there are stable communication channels. The formation of channels becomes possible due to the successive substitution of elements with the aim of achieving their desired order, which, per se, is already control. This procedure of setting up and creating an organization is, figuratively speaking, a preactive form of management actions in the most general and broadest sense. In turn, the order is set by the goals of the existence of the organizational economic system or its subsystems in the logical selection of the "outputs" of certain processes and "inputs" of others, which constitutes the chain of the economic cycle. At the same time, the fullness of the communication channels also becomes a manifestation of managerial action in cases where the sequence of elements has already been built. Thus, management is a dualistic process where the initial creation of an organization (as Drucker puts) is supplemented by a subsequent change in its performance in the continuous improvement of channels and communication flows. Only then "the planning process... motivation and control, necessary to formulate and achieve the goals [of the system]" [32] becomes realizable.
At the same time, the solution of the scientific issue of the truth of nature and the essence of management in the economic system has another approach in the organizational aspect. It is advisable to refer to some studies where management is studied from the point of view of conditionality: the reflex in them is the idea that management as a process is permissible only when the community of elements is ordered and has a coherent structure. But the initial creation of order from the chaos of free economic agents and scattered, sometimes contradictory norms and rules, is already a full-fledged management act, even when it was made in times of unconscious self-organization of the economic system. From this, one can draw a well-founded conclusion: self-organization is the "control of the invisible hand," in which the goals, tasks, methods and functions of management are dictated by a simplified desire to continue the existence, which is also true for any object in the system that is not devoid of adaptive capacity. It is important to take into account that self-organization has limited opportunities to maintain order before the threats of cardinal changes, as well as, indeed, direct control with limited available resources. All this takes the form of a revolutionary transformation with the subsequent evolutionary leap of development.

\section{UNCERTAINTY MANAGEMENT CONCEPT}

The so-called traps, or dead ends of rationality, are inherent attributes of the evolutionary movement of the economic system. They are centered in the emergence of new rules or institutions that determine the opportunities for continued growth. As a response to internal contradictions, new institutional norms-imperatives create a special uncertainty, which is projected onto the traditional types of uncertainty in the environment, decision-making and their consequences. Sometimes a failure to grow can guarantee the stability and sustainability of the continuation of life activity both for the economic system as a whole and for constituent elements, with an acceptable level of systemic or general uncertainty. The thesis that "in management ... we are interested in its organizational and economic aspects" [33] is becoming one more weighty argument to justify the primacy of organizationality.

If the emphasis is shifted from managing the behavior of economic agents to managing the order parameters, it becomes possible to influence the uncertainty, the creation of an organizationally structured structure of the economic system as a result. Thus, it is in the organizational and economic system where hidden capacities for self-organization, restoration or formation of that very organizational order are manifested. This conclusion allows drawing another extraordinary conclusion about the principle admissibility of preventive management of uncertainty.

The phenomenon of uncertainty is one of many, which fully manifests its uniqueness. The nature of uncertainty spread in the economic space, the peculiarities of its emergence and extinction, structural connectivity with the opposite manifestation of certainty, the mechanism and processes of self-organization, typological conditioning - all that makes it possible to unequivocally establish that uncertainty management, as well as certainty, is subject to 
unique and to the same extent original principles, those which create, in the end, a kind of organizational order.

It is known that the principles of management and organization as part of the preactive management activities are very diverse: from the principle of goal-setting (L.F. Urwick) to the principle of effective communication (J. Kroon [34]). A more complete description of the principles of uncertainty management is presented in the paper [35], which distinguishes the principle of tolerance, the principle of projectivity, the principle of the limit of uncertainty, the principle of interchangeability and incompatibility, the principle of plastic adjustment, the principles of simplicity and inertia, the principle of control over points of concentration of uncertainty, and the principle of management asynergy.

Particularly interesting is the eclectic consideration of uncertainty through the prism of the principles of its management and the principle of uncertainty as such. The origins of the uncertainty principle go back to the research of physical systems, for example, to the works of Heisenberg [36], Folland and Sitaram [37], and many others. The principle of uncertainty for general management systems assumes ambiguity of outcomes, variability and multi-vectors of the future development trajectory. It is also quite logical that the principle of uncertainty and the principles of uncertainty management do not have contradictions between themselves, since they describe fundamentally different processes: on the one hand, the uncertainty of the future and its invariance, and on the other hand, the conditions under which this invariance appears as a projected result in the inevitability of the stochastic evolutionary movement. Organizationality inherent in the economic system plays at the same time a key role not only in routine management, but also in the fundamental design of structural features, where the uncertainty parameter remains the decisive factor in the characterization of structural tranquility.

The internal homeostasis of the mechanism of the system tends to withstand the organizational harmony under the weight of external fluctuation perturbations, and, consequently, self-organization is the result of controlling uncertainty or certainty. The antinomicity of the expression of the management of certainty is dictated in part by the differing adherence of the elements to the preservation of the structural compilation of the system, but the main thing is that the conceptual admissibility of entropy management leads to the assumption that the management is subject to the certainty (negentropy) in changing the "rules of play" of the system, the environment, decisions and their consequences in future.

Certainly, the features of uncertainty management are extremely diverse. Further development of the problems requires in-depth study of a number of scientific problems that go beyond the scope of this study. However, in the presented research, the most topical aspects reflected in the set of fundamental principles were noted.

\section{CONCLUSION}

In the development of the presented prerequisites and significant features, the universal primacy of the organization of economic systems becomes scientifically grounded. With the apparent non-robustness of the interpretation of the notion of an organizational-economic system, its scientific investigation and discussion proceeds from a number of wellknown premises that are unquestioned. Returning to the refinement of the concept, one should give its general polyhedral definition. A system of this kind implies a paradigmatic set of aligned hierarchical structures of heterogeneous elements that fill an objectively limited space and possess the distinctive homogeneity of the behavioral reaction in the reproductive process under uncertainty, where the creation and filling of communication channels between the elements makes it possible to realize the control function. The authors have confirmed that it is in the organizational and economic system where hidden capacities for selforganization, restoration or formation of that very organizational order are manifested. In this case, organizationality is perceived as a primacy of the determinism of manifestation of uncertainty.

\section{Acknowledgment}

The study was supported by the Russian Foundation for Basic Research (RFBR), project No. 18-010-01021.

\section{References}

[1] G.B. Kleiner, "Systemic resource of economy," Voprosy ekonomiki, vol. 1,2011

[2] T.M. Baumgartner, T.R. Burns, P. DeVille, The Shaping of SocioEconomic Systems. The Application of the Theory of Actor-System Dynamics to Conflict, Social Power, and Institutional Innovation in economic life. Gordon \& Breach Publishing Group, 1986.

[3] A.J. Halbach, Economic System and Socio-Economic Development of Developing Countries: A Statistical Analysis of World Bank data, IfoInstitut für Wirtschaftsforschung, 1983.

[4] A. Szirmai, "The Dynamics of Socio-Economic Development: An Introduction", Cambridge University Press, 2005.

[5] P.S. Albin, "The Analysis of Complex Socioeconomic Systems", Lexington Books, 1975.

[6] K. Haitani, "Comparative Economic Systems: Organizational and Managerial Perspectives”, Prentice-Hall, 1986.

[7] F. Levcik, Economic Planning: Its Relation to the Socio-Economic System and to the Stages of Economic Development. Wiener Institut für Internationale Wirtschaftsvergleiche beim Österreichischen Institut für Wirtschaftsforschung, 1976

[8] M.A. Choudhury, Economic Theory and Social Institutions: A Critique with Special Reference to Canada. University Press of America, 1994.

[9] G.R. DeSouza, System Methods for Socioeconomic and Environmental Impact Analysis, Lexington Books, 1979.

[10] J. Gowdy, Coevolutionary Economics: The Economy, Society and the Environment, Springer, 1994.

[11] D.A. Novikov, "Structure of theory of management of socio-economic systems", Large-Scale Systems Control: Collection of Works, no. 24, p. $217,2009$.

[12] D. Jaffee, Levels of Socio-Economic Development Theory, 2nd ed. Greenwood Publishing Group, 1998, p. 9.

[13] M.A. Choudhury, Economic Theory and Social Institutions: A Critique with Special Reference to Canada. University Press of America, 1994.

[14] G.B. Kleiner, "Systemic theory of role management at an enterprise," in Strategic Planning and Development of Enterprises: Collection of Plenary Reports of the Thirteenth All-Russian Symposium, Moscow, April 10-11, 2012, Moscow: TSEMI RAN, 2013.

[15] G.S. Vehkanov, G.R. Vechkanova, Economic Theory, Saint Petersburg: Piter, 2010. 
[16] G.B. Kleiner, "Systemic organization of economy and systemic management," in Collection of works of the XII International Scientific Conference on the Issues of Development of Economy and Society, E.G. Yasin, Ed. Moscow: Higher School of Economics, 2012.

[17] G.B Kleiner, "Systemic paradigm and systemic management," Russian Management Journal, vol. 6, no. 3, p. 33, 2008.

[18] S.A. Sarkisyan, V.M. Akhundov, E.S. Minaev, Large Technical Systems: Analysis and Forecast of Development, Moscow: Nauka, 1977.

[19] G.A. Krayukhin, Organizational and Economic Mechanism of Innovative Development of the Enterprise, St. Petersburg: SPSEEU, 2008.

[20] E. Kovalenko, G. Zinchuk, S. Kochetkova et al., Regional Economy and Management, St. Petersburg: Piter, 2013.

[21] V.P. Kochikyan, V.I. Koshkin, and Ya.G. Lyubinetsky, Integrated System for Stimulating Technological Progress, Moscow: Mysl, 1980.

[22] A.A. Alpatov, "Organizational and Economic Mechanism of Development of Russian Entrepreneurship: Experience of Research and Practice", Kirov: Kirov Regional Publishing House, 1996.

[23] M.A. Ponomareva, "Organizational and Economic Mechanism of Transition to Sustainable Development of the Region: Concept, Theory, Practice", Moscow: RSEU, 2009.

[24] A.V. Todosiychuk, V.A. Popkov, "Organizational and Economic Mechanism of Formation and Implementation of Innovation Policy in the University", Moscow: IUO RAO, 2007.

[25] L.K. Ayupova, "The Organizational and Economic Mechanism of the Enterprise's Investment Activity", Samara: Samara Scientific Center of RAS, 2009.

[26] V.G. Tsogoev, "Organizational and Economic Mechanism of Strategic Management of the Economic Complex of a Depressed Region", Vladikavkaz: Ir, 2000.

[27] M.I. Rimer, A.D. Kasatov, N.N. Matienko, "Economic Evaluation of Investments", St. Petersburg: Piter, 2006.

[28] S.A. Sarkisyan, V.M. Akhundov, E.S. Minaev, "Large Technical Systems: Analysis and Forecast of Development", Moscow: Nauka, 1977.

[29] V.O. Fedorovich, "Composition and structure of the organizational and economic mechanism for managing the property of large industrial corporate entities", Siberian Financial School, no. 2, 2006.

[30] A.A. Kulman, "Economic Mechanisms", Moscow: Progress, 1993.

[31] P.F. Drucker, "A new discipline," Success, p. 18, January-February 1987.

[32] M.H. Mescon, F. Albert, F. Khedouri, "Basics of Management", Moscow: Delo, 2000, pp. 48, 69.

[33] V.P. Kochikyan, V.I. Koshkin, and Ya.G. Lyubinetsky, "Integrated System for Stimulating Technological Progress", Moscow: Mysl, 1980.

[34] J. Kroon (Ed.), Algemene Bestuur. Preioria: Kagiso, 1995, pp. 390-391.

[35] E.A. Kuzmin, "Principles of uncertainty management", Problems of Risk Analysis, vol. 11, no. 4, pp. 52-69, 2014.

[36] W. Heisenberg, "Über den anschaulichen Inhalt der quantentheoretischen Kinematik und Mechanik," Zeitschrift für Physik, no. 43, 1927.

[37] G. Folland and A. Sitaram, "The uncertainty principle: a mathematical survey," Journal of Fourier Analysis and Applications, vol. 3, no. 3, 1997. 